\author{
Abstracta Iranica \\ Abstracta Iranica Revue bibliographique pour le domaine irano-aryen \\ Volume 37-38-39 | 2018 \\ Comptes rendus des publications de 2014-2016
}

\title{
Bernard O'Kane. " Arthur Upham Pope and the Study of Persian Islamic Architecture »
}

Sarah Piram

\section{(2) OpenEdition \\ Journals}

Édition électronique

URL : http://journals.openedition.org/abstractairanica/42725

DOI : 10.4000/abstractairanica.42725

ISBN : 1961-960X

ISSN : 1961-960X

Éditeur :

CNRS (UMR 7528 Mondes iraniens et indiens), Éditions de l'IFRI

Référence électronique

Sarah Piram, « Bernard O'Kane. " Arthur Upham Pope and the Study of Persian Islamic Architecture » », Abstracta Iranica [En ligne], Volume 37-38-39 | 2018, document 10, mis en ligne le 10 mars 2018, consulté le 29 septembre 2020. URL : http://journals.openedition.org/abstractairanica/42725 ; DOI : https://doi.org/10.4000/abstractairanica.42725

Ce document a été généré automatiquement le 29 septembre 2020

Tous droits réservés 


\title{
Bernard O’Kane. « Arthur Upham Pope and the Study of Persian Islamic Architecture »
}

\author{
Sarah Piram
}

\section{RÉFÉRENCE}

Bernard O'Kane, « Arthur Upham Pope and the Study of Persian Islamic Architecture », in Yuka Kadoi (dir.), Arthur Upham Pope and A New Survey of Persian Art, LeydeBoston: Brill, 2016, p. 111-124.

1 Dans cette contribution, extraite de l'ouvrage Arthur Upham Pope and A New Survey of Persian Art, publié à la suite d'un colloque international à l'Art Institute de Chicago (9-10 septembre 2010), Bernard O'Kane s'intéresse à la figure de l'orientaliste américain Arthur Upham Pope (1881-1969) et à son étude de l'art iranien de période islamique.

2 O'Kane commence par dresser un portrait critique de Pope. Il considère ainsi que les faiblesses de Pope se manifestaient surtout dans ses analyses, jugées parfois lacunaires, et qui, selon O'Kane, soulignaient un manque de rigueur scientifique. L'auteur reconnaît cependant que, à de nombreux égards, Pope fut un personnage fort habile. Son éloquence et ses talents photographiques furent reconnus de tous ses contemporains. O'Kane rappelle notamment le rôle joué par Pope pour permettre l'accès aux mosquées pour les non-musulmans auprès de Rezâa Shâh Pahlavi (r. 1925-1941).

3 Son incontournable Survey of Persian Art. From Prehistoric Times to the Present (Oxford University Press, publié en six volumes entre 1938 et 1939) a fait l'objet de nombreux éloges mais également de critiques, parfois acerbes, de sa vision générale de l'art persan et de ses constatations. Parmi ces critiques, O'Kane cite Meyer Schapiro (1904-1994), Myron Bement Smith (1897-1970), ainsi qu'André Godard (1881-1965). Ce dernier attaqua Pope à diverses reprises : d'abord dans la préface du premier numéro d' 
Athārr-é İrān, la revue des Services archéologiques de l'Iran, puis dans un compte-rendu du Survey, cette fois avec une référence subtile à Beaumarchais: "il fallait un calculateur, on appela un danseur ». O'Kane montre toutefois combien le rôle de Pope fut majeur pour la connaissance de l'art iranien de période islamique, contrairement à Godard qui s'intéressa surtout à la période préislamique. O'Kane appuie ici son jugement sur le nombre de chapitres dédiés à la période islamique dans les principaux ouvrages des deux auteurs : sept chapitres sur neuf dans le Persian Architecture de Pope (1965), contre un sur cinq chez Godard dans son L'Art de l'Iran (1962). Mais peut-être pourrait-on remettre en question la pertinence de cette observation. Et si Pope constitue sans conteste une figure majeure pour l'art iranien de période islamique, o'Kane montre qu'il a arrêté son étude à la fin de la période safavide, jugeant l'art qājār de « grotesque and stupid».

\section{AUTEURS}

\section{SARAH PIRAM}

Doctorante en histoire de l'art contemporain, Université Paris-Nanterre 